Dr Peter John Bowers died on 15 May 2018 at the age of 71 years from complications of pneumonia. He was for many years a key senior leadership figure and driver for mental health services across the North West of England. His entire consultant career was spent as National Health Service (NHS) consultant in child and adolescent psychiatry across Tameside and Glossop (the now-combined Pennine Care NHS Specialist Mental Health Trust), where he was Medical Director from 1993 to 2000 . He was dedicated and highly effective both as a medical leader, with patient care at the forefront of his concern, and as a manager. He was Chair of the Regional Group of Child and Adolescent Psychiatrists for many years, presiding over countless quality improvements, strategies, developments and delivery. Peter held strong team values and, in his clinical work, energetically applied medical and neurological frameworks of understanding alongside a systemic and family therapy ethos.

The breadth and depth of Peter's skill set made him a uniquely popular trainer in child and adolescent psychiatry across the North Western deanery. Nationally, he served on the Child and Adolescent Faculty Executive. Many consultants in child and adolescent mental health services remain ever grateful for his wise supervision. His own special interests included working with children with neurodevelopmental disorders and intellectual disability. Before and following retirement, he performed an extensive range of expert witness and medico-legal work, including work with local authorities in family court proceedings. Throughout his life he was characterised by his passion and love of learning, his generous sharing of his knowledge and his humanity, integrity and eloquence.

Peter Bowers was born in Sunderland. As a child, he attended Queen Elizabeth Grammar School, where he excelled in both science and arts. He first took a degree in chemistry in the University of London and then attended Manchester University Medical School, graduating in 1973 with double honours. He remained in the North West to complete postgraduate training in paediatrics and psychiatry, and then completed higher specialist training in child and adolescent psychiatry.

From his childhood, Peter had a passion for the performing arts. His mother had instilled a love of theatre in him. Throughout his career, along with his wife and children, he was highly active in theatre work, performing or directing all year round in productions for the Northenden Players and for the South Manchester Operatic Society. The family home 'Bowers Towers' is bedecked with posters and photographs from innumerable productions, in which he played key roles in comedy, Shakespeare, musicals and drama. His last role, performed only 4 months before his death, was as Sergeant Wilson in Dad's Army. He also worked tirelessly for the South Manchester local community. Using his considerable charm, persistence and superbly persuasive public speaking, he secured real positive change for the area through his work with the South East Fallowfield Residents Group, of which he was Chair.

His family life was the ultimate source of pride and joy to him. In 1970, he married Lesley, whom he had known since childhood. They had three children, Juliet, Jonathan and Anthony and he had one grandchild, Harry. He will be remembered with love and affection by his family, by their innumerable friends, work colleagues and by former patients.

Anna Kushlick and Sue Bailey

doi:10.1192/bjb.2018.93

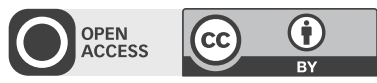

(c) The Authors 2018. This is an Open Access article, distributed under the terms of the Creative Commons Attribution licence (http://creativecommons.org/ licenses/by/4.0/), which permits unrestricted re-use, distribution, and reproduction in any medium, provided the original work is properly cited.

\section{Narendra Nath Wig, MD, FRCPsych (Hon.), DPM}

Formerly Professor of Psychiatry, All India Institute of Medical Sciences, New Delhi, India and Regional Advisor for Mental Health, Eastern Mediterranean Region, World Health Organization

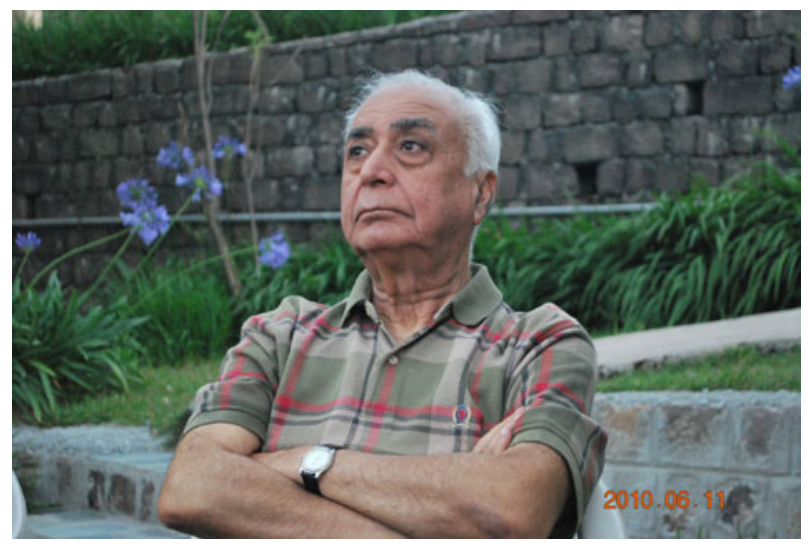

During the late 1970s, Narendra Wig, who died at the age of 88 years on 12 July 2018, led a highly successful community mental health initiative in rural areas of India from the Postgraduate Institute, Chandigarh. His pioneering work in this field led to significant changes in the approach to mental health services, not only in India but in many other economically developing countries. He organised national level meetings in Delhi in 1982, which produced a National Mental Health Programme (NMHP) that insisted on mental health forming a part of the total health programme. He wanted to see psychiatric wards moving out of mental hospitals and developing in general medical hospitals. So passionate was he in advocacy of a community psychiatric approach that, after the Delhi meetings, he and some colleagues called on the then Health Secretary, waking him late at night and still in his nightclothes, to urge him to incorporate the NMHP into the national health strategy. ${ }^{1}$

This work led to his appointment as Regional Advisor in Mental Health to the World Health Organization (WHO) Middle East Region, where he spread his philosophy to the 22 countries, from Morocco to Pakistan. In particular, he 
contributed to the development of mental health programmes in Pakistan and school mental health programmes in Egypt. His vision was to make the benefits of modern psychiatry available to all sections of the population, rich and poor; to combine biomedical and psychosocial approaches to psychiatric practice; to use emerging technologies and to make psychiatry more relevant to a country's cultural needs.

Narendra pioneered research and clinical developments in many other areas of psychiatry. He was among those involved in the ICD-9 (1978) and ICD-10 (1992) revisions of the WHO psychiatric classification system, emphasising throughout the importance of taking into account cultural variations in the presentation and course of psychiatric disorders. He contributed significantly to studies of the phenomenology of acute psychosis and schizophrenia, noting differences in levels of criticism and emotional expression in Indian compared with Western European samples. He was a collaborator in the WHO collaborative studies looking at the outcome of people with schizophrenia in both low- and middle-income countries and high-income countries. Alongside his work in classification, he played an active part in the development of reliable and valid tools for psychological assessment in India. Unusually for a psychiatrist, he studied the emotional sequelae of family planning measures. He and his colleagues carried out a number of studies on drug, especially cannabis, use.

Narendra was born in 1930 in Gujranwala, Punjab, now in Pakistan. After the Partition of India, his family moved to Bareilly, in Uttar Pradesh, in northern India. He won a scholarship to King George's Hospital Medical College in Lucknow and qualified MB, BS in 1956. Not long after qualification, he was awarded a Rockefeller Foundation Scholarship and went both to the UK, where he was placed at the Maudsley Hospital, and to the USA for postgraduate training. On his return, he moved to Chandigarh to found the Department of Psychiatry at the Postgraduate Medical Institute there. In the early 1970s, he set about developing community psychiatric services in Raipur Rani. In 1976, his Department became a WHO Collaborating Centre. In 1980 he moved to Delhi to head the Psychiatric Department of the All India Institute of Medical Sciences. In 1984 he was appointed WHO Regional Advisor in Mental Health at the Eastern Mediterranean Regional Office. After making a notable contribution, he retired from WHO in 1991 and in 1997 was made Emeritus Professor of Psychiatry at the Postgraduate Institute in Chandigarh.
After retirement, Narendra continued to work for a further 25 years in an unpaid capacity as a psychiatrist delivering free mental healthcare to the poorest of the poor in rural villages and urban slums.

Naren had a remarkable personality. He was warm, gentle, mild mannered, calm and moderate. As a professional, he was able, clinically astute and vastly knowledgeable. He was venerated by students and trainees who saw him as a guru who educated them not only in the practice of clinical medicine and psychiatry but also in lifestyle and life conduct. A guru is more than a teacherhe reveals the meaning of life, and this is how many of those who came into contact with Naren came to see him.

Naren received many honours. In particular, in 1991 he was the first Indian psychiatrist to be awarded the Honorary Fellowship of the Royal College of Psychiatrists. In 2003 the Bombay Psychiatric Society awarded him their lifetime achievement award. In 2004 a psychiatric centre in Lahore, Pakistan was named after him.

Outside of psychiatry, he had many interests including Urdu poetry, particularly that by Mirza Ghalib, and birdwatching. He and his wife, Veena, whom he married in 1963, were a devoted couple who had two sons, Siddartha and Anish. Veena predeceased him and he is survived by his sons and grandchildren.

\section{Reference}

1 Murthy SR. Prof. Narendra Wig - a man ahead of his time. In Psychiatry in India: Training and Training Centres (eds TS Rao, A Tandon): 547-70. Indian Psychiatric Society, 2015.

Raghu Gaind

doi:10.1192/bjb.2018.103

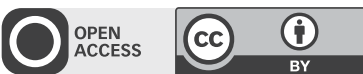

(c) The Author 2019. This is an Open Access article, distributed under the terms of the Creative Commons Attribution licence (http://creative commons.org/licenses/by/4.0/), which permits unrestricted re-use, distribution, and reproduction in any medium, provided the original work is properly cited. 